\title{
Plutonium Immobilization Can Loading Equipment Review
}

by

E. Kriikku

Westinghouse Savannah River Company

Savannah River Site

Aiken, South Carolina 29808

c. Ward

L. Hamilton

M. Stokes

B. Randall

J. Steed

R. Jones

DOE Contract No. DE-AC09-96SR18500

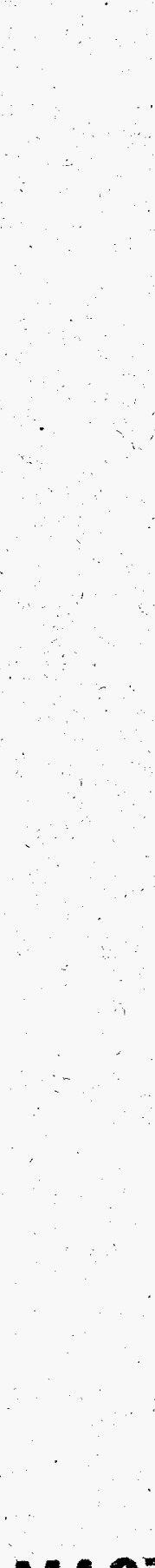

MASTER,

This paper was prepared in connection with work done under the above contract number with the U.S. Department of Energy. By acceptance of this paper, the publisher and/or recipient acknowledges the U.S. Government's right to retain a nonexclusive, royalty-free license in and to any copyright covering this paper, along with the right to reproduce and to authorize others to reproduce all or part of the copyrighted paper. 


\section{DISCLAIMER}

This report was prepared as an account of work sponsored by an agency of the United States Government. Neither the United States Government nor any agency thereof, nor any of their employees, makes any warranty, express or implied, or assumes any legal liability or responsibility for the accuracy, completeness, or usefulness of any information, apparatus, product, or process disclosed, or represents that its use would not infringe privately owned rights. Reference herein to any specific commercial product, process, or service by trade name, trademark, manufacturer, or otherwise does not necessarily constitute or imply its endorsement, recommendation, or favoring by the United States Government or any agency thereof. The views and opinions of authors expressed herein do not necessarily state or reflect those of the United States Government or any agency thereof.

This report has been reproduced directly from the best available copy.

Available to DOE and DOE contractors from the Office of Scientific and Technical Information, P.O. Box 62, Oak Ridge, TN 37831; prices available from (615) 576-8401.

Available to the public from the National Technical Information Service, U.S. Department of Commerce; 5285 Port Royal Road, Springfield, VA 22161. 


\section{DISCLAIMER}

Portions of this document may be illegible electronic image products. Images are produced from the best available original document. 


\section{Plutonium Immobilization \\ Can Loading Equipment Review (U)}

May 1, 1998

Westinghouse Savannah River Company

Savannah River Site

Aiken, SC 29808 


\title{
Plutonium Immobilization Can Loading Equipment Review (U)
}

The following Plutonium Immobilization Can Loading Team members contributed to this report.

\author{
Bill Randall \\ NMS\&S \\ Jim Steed \\ NMS\&S \\ Robert Jones \\ NMS\&S \\ Clyde Ward \\ SRTC/EES \\ Mitchell Stokes \\ SRTC/EES \\ Lane Rogers \\ SRTC/EES \\ Lee Hamilton \\ SRTC/EES \\ Greg Dyches \\ SRTC/EES \\ James Fiscus \\ SRTC/EES \\ Eric Kriikku \\ SRTC/EES
}




\section{TABLE OF CONTENTS}

SUMMARY

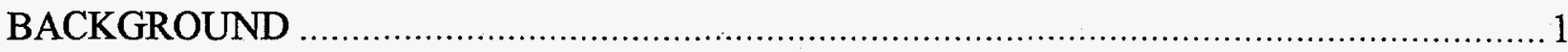

PLUTONIUM IMMOBILIZATION REQUIREMENTS ......................................... 1

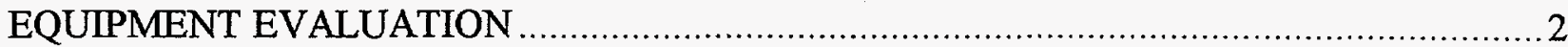

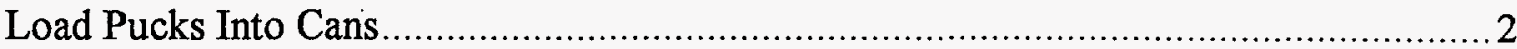

Transport Trays From Elevator ............................................................... 2

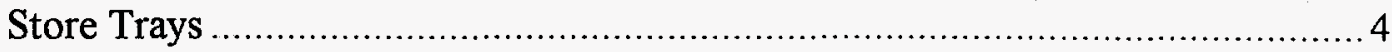

Load Pucks Into Can................................................................................. 5

Fill Can with Helium and Insert Plug .................................................... 6

Transport Plugs into Glovebox................................................................. 7

View Operations ............................................................................ 8

Bagless Can Loadout (Weld Process to Seal Can) ............................................. 8

Bagless Transfer............................................................................... 9

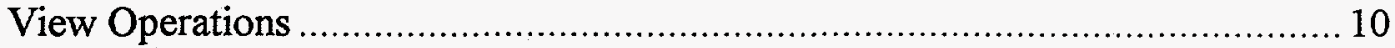

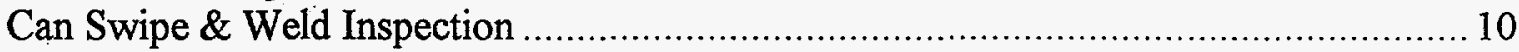

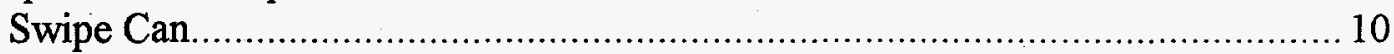

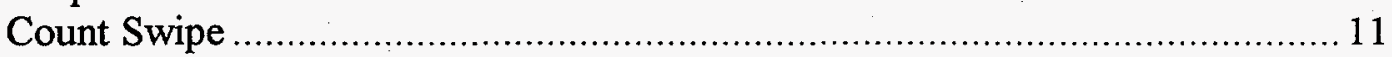

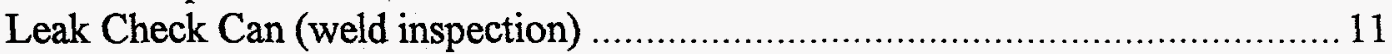

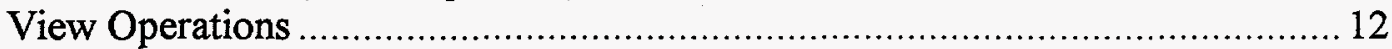

Open Can and Remove Pucks (Reject Cans) ...................................................... 12

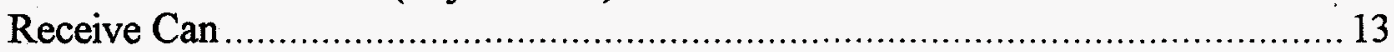

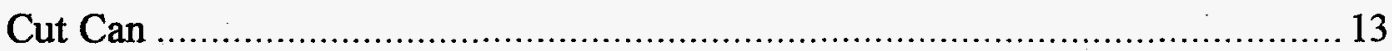

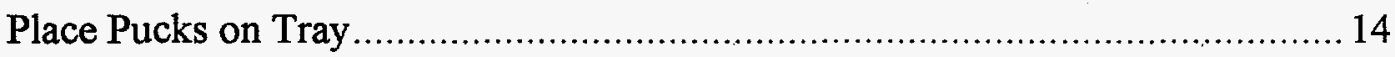

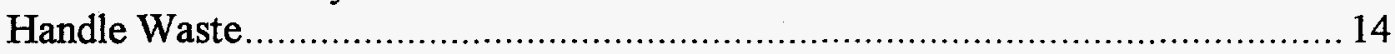

Transport Tray to Puck Loading Robot ...................................................... 14

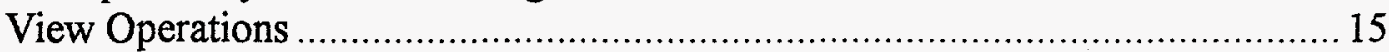

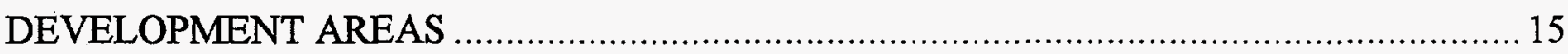

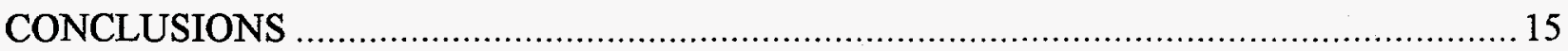

Attachment 1 - Plutonium Immobilization Plant Process Flow Drawing .............................. 17

Attachment 2 - Plutonium Immobilization Can Loading Detailed Flow Diagram ................... 18 


\section{SUMMARY}

The Plutonium Immobilization Facility will encapsulate plutonium and depleted uranium in ceramic pucks and seal the pucks inside welded cans. Remote equipment will place these cans into magazines and the magazines into a Defense Waste Processing Facility (DWPF) canister. The DWPF will fill the canister with glass for permanent storage. This report lists the operations required to complete the Can Loading steps on the Pu Immobilization Plant Flow Sheets and evaluates the equipment options to complete each operation. This report recommends the most appropriate equipment to support Plutonium Immobilization Can Loading operations.

\section{BACKGROUND}

The Plutonium Immobilization Facility design will minimize operator exposure and prevent the spread of contamination. To accomplish these goals, a system is required to package contaminated materials in clean containers and not release contamination. Traditional methods of removing plutonium from process gloveboxes in preparation for packaging involves the use of bagout procedures utilizing plastic bags. This method is not acceptable in the Plutonium Immobilization Facility. Engineers at the Savannah River Site have developed a system for removing plutonium from a glovebox directly into an all metal, welded, leaktight container, free of external contamination. The process, known as bagless transfer, utilizes a Tungsten-Inert-Gas (TIG) welding process to seal plutonium in a can. The process then separates the transfer can from the glovebox environment while maintaining glovebox and can integrity. A semi-automated bagless transfer unit is in operation at the Savannah River Site FB-Line Plutonium Facility. The Plutonium Immobilization Can Loading operations will use this system as a baseline.

\section{PLUTONIUM IMMOBILIZATION REQUIREMENTS}

The Plutonium Immobilization facility must produce approximately 560 pucks per day to meet production requirements. The can loading system must be able to automatically load 24 pucks per hour at the minimum into puck cans. The puck cans are loaded into magazines, then the magazines are loaded into racks already inside the DWPF canisters. The DWPF canisters are filled with approximately 91 inches of glass to totally encapsulate the puck cans, magazines, and racks in the glass.

Normal can loading system operations will be performed automatically and/or remotely. Table 1 shows the Can Loading Process steps shown on the Pu Immobilization Plant Flow Sheets (see Attachment 1).

Table 1 - Can Loading Process Steps

\begin{tabular}{cll}
$\begin{array}{c}\text { Unit Operation } \\
\text { Number }\end{array}$ & $\begin{array}{c}\text { Module } \\
\text { Number }\end{array}$ & Title \\
\hline IC-13 & FSI-7 & Load Pucks into Cans \\
IC-13 & FSI-7 & Bagless Can Loadout (Weld Process to Seal Can) \\
IC-14 & FSI-7 & Can Swipe \& Weld Inspection \\
IC-14 & FSI-7 & Open Can \& Remove Pucks (Reject Cans)
\end{tabular}




\section{EQUIPMENT EVALUATION}

The following paragraphs break the can loading flow sheet steps into detailed sub-steps, (see Attachment 2). Equipment options for each sub-step are evaluated and a recommendation is made for each sub-step.

\section{Load Pucks Into Cans}

Table 2 shows the process steps required to load pucks into cans and the equipment options for each step. The following paragraphs discuss the advantages and disadvantages of each equipment option and recommends an equipment option based on the advantages and disadvantages.

Table 2 - Load Pucks Into Cans

\begin{tabular}{ll} 
Process Steps & Equipment Options \\
\hline Transport trays from elevator & Magnetically coupled linear transport \\
(overhead material transport elevator) & Belt conveyor \\
& $\begin{array}{l}\text { Roller conveyor } \\
\text { Magnetically coupled air cylinder }\end{array}$ \\
Store trays (two) & Custom vertical lift \\
& Conveyor lift and lateral transfer \\
& Pick and place machine for trays \\
Load pucks into can & Pick and place machine \\
& Cartesian robot \\
& Jointed arm robot \\
& SCARA robot \\
Fill can with helium, insert plug & Helium glovebox and lance \\
& Custom hood \\
Transport plugs into glovebox & Preload plugs in cans \\
& Plug sphincter seal and conveyor \\
View operations & Airlock and conveyor \\
& Black and white camera \\
& Color camera \\
& Window viewing
\end{tabular}

\section{Transport Trays From Elevator}

The four options to transport puck trays from the overhead material transport system elevator into the Can Loading glovebox are; magnetically coupled linear transport, belt conveyor, roller conveyor, and magnetically coupled air cylinder (or rodless air cylinder). This system will also returns empty trays to the elevator. A magnetically coupled linear transport is a passive cart on rails with a series of magnets on the cart bottom inside the containment system. Outside the containment is a linear actuator that moves a corresponding magnet set. When the linear actuator moves the magnet set outside the containment, the cart inside the containment moves with it. The following lists the advantages and disadvantages of a magnetically coupled linear transport system. 
Advantages

* The system uses a minimal amount of equipment in the containment.

* Position feedback sensors are outside the containment.

* The system is compatible with airlocks.
Disadvantages

* The system is not commercially available, but most components are available.

* The system requires additional equipment to load trays.

A belt conveyor is a long belt that is wrapped around two pulleys and one pulley is motor driven. The belt is supported between the pulleys and the payload rides on the belt. The following lists the advantages and disadvantages of belt conveyors.

Advantages

* The system is inexpensive.

* It is highly durable.

* It is commercially available.

* It is easily adaptable to a magnetically coupled motor (outside containment).

* The system can use flexible belts allow turns and elevation changes.

* The system has commercially available accessories.
Disadvantages

* The drive system is usually single direction.

* The system has many contamination entrapment areas.

* Position feedback requires additional sensors.

* The belt becomes waste.

* The system is difficult to decontaminate and repair.

* The system requires multiple drives to pass through airlocks.

* The system uses a lot of equipment in glovebox.

* The belt can transfer contamination.

A roller conveyor is a series of rollers (long thin cylinders) in a frame and a belt or chain that drives all the rollers. The payload rides on the rollers and is passed from one roller to the next. The following lists the advantages and disadvantages of roller conveyors.

Advantages

* They can handle large payloads.

* They are commercially available.

* They use low friction transfers.

* They come in long lengths.
Disadvantages

* Most models use chains or belts which are difficult to decontaminate and repair.

* The system has many contamination entrapment areas (each roller).

* Position feedback requires addition sensors inside the containment.

* The system uses a lot of equipment in glovebox.

A magnetically coupled air cylinder, or rodless air cylinder, is a cart on rails with a magnet on the cart bottom. A pipe between the rails contains a magnet and a gas or liquid is forced through the pipe to move the magnet. When the magnet in the pipe moves, the cart moves with it. The following lists the advantages and disadvantages of magnetically coupled air cylinders. 
Advantages

* They are commercially available.

* Long strokes are available.

* They have minimal decontamination and repair problems.

* The systems are compact.
Disadvantages

* They use pressurized gas or liquid.

* Position feedback requires additional sensors.

* It is difficult to control low speeds with the gas system.

* Liquid system is not glovebox compatible.

* They require custom airlock transfer systems.

* Dusty environments would quickly wear rail bearings.

This report recommends the use of magnetically coupled linear transport system to transport trays from the elevator to the Can Loading glovebox due to the minimal amount of equipment used inside the containment.

\section{Store Trays}

The three ways to store trays are; a custom vertical lift, conveyor lift and lateral transfer, and a tray pick and place machine. The system must be able to store two trays at the minimum, one with new pucks on it and an empty tray ready to leave. A custom vertical lift is two vertical linear actuators on either side of the tray. Lifting fixtures on the actuators start below the tray and are driven upward. The fixtures lift the tray from the transport cart, allowing the cart to move away without the tray. The following lists the advantages and disadvantages to a custom vertical lift.

\section{Advantages}

* The system uses a minimal amount of equipment inside the containment.

* They use a minimal amount of floor space in the containment.

* The system motors can be outside containment via a magnetic coupling.

* They integrate well with cart/tray transport system.

* The design may be used to bottom load a furnace.
Disadvantages

* Storage space is limited by vertical space.

* They are not commercially available.

* The top tray is the only accessible tray.

* The system requires development.

A conveyor lift and lateral transfer is two short belt conveyors that start below the rollers on a roller conveyor. The short belt conveyors are perpendicular to the roller conveyor direction of travel, a few inches apart, and between rollers. When the payload is over the short belt conveyors, they are raised upward lifting the payload off the rollers. The belt conveyors are engaged and the payload is carried laterally from the roller conveyor. The following lists the advantages and disadvantages of the a conveyor lift and lateral transfer.

Advantages

* They are commercial available.

* All trays are accessible from the top.
Disadvantages

* They use the maximum amount of floor space.

* They require complicated equipment inside the containment.

* Storage is limited by floor space. 
A pick and place machine is typically two or three pneumatic actuators joined in series and usually has a gripper or lifting tool on the last actuator. The resulting device can pick up a payload at point $A$ and deliver it to point $B$. The machine is designed for a specific task and can only perform this task. Accessories can be added to allow the machine to perform more complicated tasks such as, pick up the payload at point $\mathrm{A}$ and deliver it to point $\mathrm{B}, \mathrm{C}$, or D. The following lists the advantages and disadvantages of a pick and place machine.

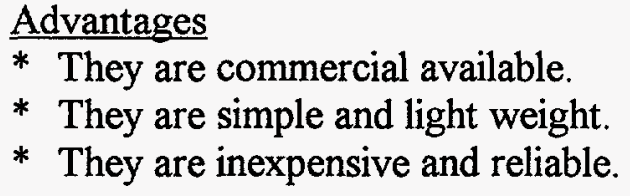

Disadvantages

* They use a large amount of floor space.

* They have a limited reach.

* They require accessories to pick up and drop off items from various positions.

* They are usually pneumatic.

This report recommends the use of a custom vertical lift to store trays in the Can Loading glove box due to the minimal amount of equipment used inside the containment.

\section{Load Pucks Into Can}

The four ways to load pucks into cans are; a pick and place machine, Cartesian robot, jointed arm robot, and SCARA robot (Selectively Compliant Arm for Robotic Assembly). The primary challenges are the long vertical motion required to load pucks into a can, approximated 30 inches, and the tight clearance between the puck outside diameter and the can inside diameter. The previous "Store Trays" section describes a pick and place machine and lists its advantages and disadvantages.

A Cartesian robot is a multi-jointed computer controller machine. The first three joints are linear actuators providing $\mathrm{X}, \mathrm{Y}$, and $\mathrm{Z}$ directions of travel. Further joints or tooling can be mounted to the last linear joint. All joints have position sensors and the control computer uses this sensor data to control joint position, speed, and acceleration. The following lists the advantage and disadvantages of a Cartesian robot.

Advantages

* They have a rectangular work envelope.

* They require minimal or no floor space.

* They can carry large payloads.

* They can use electric motors.

* Systems are commercially available:

* They are programmable for many tasks.
Disadvantages

* The long pieces (linear actuators) are difficult to replace.

* They use complicated equipment inside the containment.

A jointed arm robot is a multi-jointed computer controlled machine. The jointed arm robot typically has a three to six rotational actuators linked in series and is mounted to a base plate. Between some or all of the rotational actuators are solid links to give the arm length. All joints have position sensors and the control computer uses this sensor data to control joint position, speed, and acceleration. The following lists the advantages and disadvantages of a jointed arm robot. 
Advantages

* They are commercially available.

* They typically use electric motors.

* They can perform dexterous tasks.

* They are programmable for many tasks.
Disadvantages

* They use complicated equipment in the containment.

* They are hard to replace in a glovebox environment due to weight and shape.

* They have a spherical work envelope and it doesn't match the rectangular glove box shape.

The typical SCARA robot is a three jointed computer controlled machine. The robot base is mounted to a horizontal plane. The first joint is a rotational joint that rotates about a vertical base center line and connects the base to the first link. The second joint is a rotational joint that rotates about a vertical line and connects the first link to the second link. The third joint is a linear joint that moves vertically and is mounted on the end of the second link. The SCARA robot is designed to place small components into tight places, such as computer chips on a circuit board. The following lists the advantages and disadvantages of a SCARA robot

Advantages

* They are commercially available.

* They are programmable for many tasks.

* They can make compliant vertical moves.
Disadvantages

* They use complicated equipment in the containment.

* They are hard to replace in a glovebox environment due to shape.

* The cylindrical work envelope doesn't match the rectangular glove box shape.

* They require modification to handle a long vertical motion (30+ inches).

This report recommends the use of a Cartesian robot to load pucks into cans in the Can Loading glove box. Its large rectangular work envelope allows it to perform can loading operations, like loading pucks in cans, and reject can operations, like moving cans, without other equipment.

\section{Fill Can with Helium and Insert Plug}

The two ways to fill the puck can with helium are; maintain a helium atmosphere in the glovebox or use a custom hood. The puck can must be filled with helium for the weld leak test. The following lists the advantages and disadvantages to maintaining a helium environment in the Can Loading glovebox.

\section{Advantages}

* The plug insertion task is simple.

* The system requires minimal equipment in the containment.
Disadvantages

* Method requires development.

* Method requires airlocks and tight seals.

* Helium atmosphere may not be compatible with facility ventilation system.

* Method requires large quantities of helium.

A custom helium hood is a device that is placed over the puck can after it is full of pucks. The device seals to the can, removes the air from the can, injects helium into the can, and places the can plug into the can. The following lists the advantages and disadvantages of a custom helium hood. 
Advantages

* The method is a proven.

* The method requires a small amount of helium.

* Special glovebox airlock doors are not required.

* The method guarantees the helium quantity in puck can.
Disadvantages

* The device needs to be developed.

* The method uses complicated equipment in the containment.

* The system will require regular seal replacement.

This report recommends the use of a helium atmosphere in the Can Loading glovebox to fill the cans with helium. This allows the puck loading robot to insert the plug and minimizes the equipment in the containment. This assumes that the requirements to maintain a helium atmosphere in the glovebox are feasible. Further investigations into the helium glovebox atmosphere will reveal these requirements and a future report will address this issue with better information.

\section{Transport Plugs into Glovebox}

The three ways to transport puck can plugs into the Can Loading glovebox are; to preload plugs in puck cans, use a plug sphincter seal and conveyor, and use an airlock and conveyor. The plug is a hollow metal cylinder with closed ends and is inserted into the puck can after all the pucks. The weld process fuses the plug to the puck can wall and the fused can/plug are cut. Half the plug forms the puck can top and the other half forms the stub bottom. The following lists the advantages and disadvantages to pre-loading the plugs in the puck cans.

Advantages

* The method ensures the plug will fit in the can.

* The method requires no equipment.

* The method requires no dedicated glovebox doors.

\section{Disadvantages}

* The puck loading system must be able to remove the plug.

* The concept needs to be tested.

A sphincter seal is a hole in the glovebox the size and shape of the plug. The plug passes through several gaskets as it is pushed through the hole. Typically, a plug is left in the seal to maintain containment and the next plug is used to push the plug in the seal into the glovebox. Plugs only travel into the glovebox so contamination is not drawn out. The following lists the advantages and disadvantages of a plug sphincter seal and conveyor.

Advantages

* The design is similar to puck can sphincter seal.

* The system is simple.
Disadvantages

* The seals and conveyor will require maintenance.

* The conveyor is inside the containment.

An airlock and conveyor are a small chamber, two doors; and a conveyor. The first door is between the outside atmosphere and a chamber and the second door is between the chamber and the glovebox. An item entering the glovebox encounters both doors closed. The first door opens and the conveyor moves the item into the chamber. The first door closes sealing the item in the airlock. The chamber atmosphere is removed and replaced with the glovebox atmosphere. The second door opens and the conveyor moves the item into the glovebox. The second door closes 
and the chamber can be cleaned or the atmosphere purified. The airlock and conveyor system allows items to enter the glovebox without the glovebox atmosphere escaping. The following lists the advantages and disadvantages of an airlock and conveyor system.
Advantages
* The method is proven and simple.
Disadvantages
* The conveyor and airlock doors require maintenance.

This report recommends pre-loading the plug in the puck can due to the fact that it requires no equipment and it ensures the plug will fit in the can. The puck loading system will have to remove the plug before puck loading operations begin.

\section{View Operations}

The three ways to view remote operations are; black and white camera, color camera, and window viewing. The can loading operations will be computer controlled, but operations require some viewing for quality assurance and safety. The following lists the advantages and disadvantages to using black and white cameras.
Advantages
* They cost less than color cameras.
* They have higher resolution.

Disadvantages

* They can't display colors. Useful information can be in object color.

The advantages and disadvantages to using color cameras are the inverse of the black and white camera reasons.

The advantages to using windows are; they are inexpensive, reliable, and simple. The disadvantage to using windows is personnel will receive radiation dose.

This report recommends the use of color cameras to view operations due to the fact that color images will give operators the most information possible. This report also recommends placing windows in the gloveboxes for viewing maintenance operations.

\section{Bagless Can Loadout (Weld Process to Seal Can)}

Table 3 shows the process steps required to perform can sealing operations and the equipment options for each step. The following paragraphs discuss the advantages and disadvantages of each equipment option and recommends an equipment option based on the advantages and disadvantages.

\begin{tabular}{ll}
\multicolumn{2}{c}{ Table 3 - Bagless } \\
& Can Loadout (Seal Can) \\
Process Steps & Equipment Options \\
\hline Bagless Transfer & SRS Bagless System \\
& BNFL Bagless System \\
& Radwaste Conditioning Bagless System \\
& Central Research Labs Bagless \\
& Transfer System \\
View Operations & Black and white camera \\
& Color camera \\
& Window viewing
\end{tabular}




\section{Bagless Transfer}

The four ways to package the pucks into cans without using plastic bags are; the SRS bagless system, BNFL bagless system, Radwaste Conditioning Ltd bagless transfer system, and Central Research Labs bagless system. The SRS bagless transfer places a metal can in a sphincter seal, the seal is in the glovebox floor. Items in the glovebox are loaded into the can, then a hollow plug is placed in the can. A TIG welder fuses the plug to the can wall and a pipe cutter cuts the can at the weld area. This cut separates the sealed can from the sealed stub left in the glovebox sphincter seal. The plug top half is the stub bottom and the plug bottom half is the can top. The following lists the advantages and disadvantages of SRS bagless transfer system.

\section{Advantages}

* The method is proven in radioactive service.

* The system requires minimal development costs.

* Technical support is in place at SRS.

* The methods requires minimal technical risk.

\section{Disadvantages}

* The system is not commercially available.

* The system produces a stub as waste.

The BNFL Bagless Transfer system is similar to the SRS method, but it uses a laser to weld and cut the can and the can is in a horizontal position. The following lists the BNFL Bagless Transfer system advantages and disadvantages.

\author{
Advantages \\ * The system is commercially \\ available. \\ * The system is tested.
}

Disadvantages

* The system has not been used for radioactive service in the United States.

* The system details are not known since they are proprietary BNFL knowledge.

* The system uses complicated equipment inside the containment.

* Laser systems require special operator training.

The Radwaste Conditioning Ltd bagless transfer system is reusable double lid system. The glovebox has a special port and port door, while the can lid seals the can. The can is mated to the glovebox at the special port. The door seals to the can lid, the lid is released from the can, and the door from the port. The door and lid enter the glovebox and items enter the can. The door and lid assembly are reinstalled, the lid seals to the can, the door seals to the port, and the door releases the lid. The sealed can is released from the glovebox. The following lists the advantages and disadvantages to the Radwaste Conditioning bagless transfer system.

Advantages

* The system is commercially available.

* The system has a radioactive service record.
Disadvantages

* The cans are not welded shut.

* The system is manually operated.

* The system requires development to operate remotely. 
The Central Research Labs bagless transfer system is similar in concept to the Radwaste Conditioning system, but it uses a different mechanical seal and locking device. The Central Research Labs system has the same advantages and disadvantages as the Radwaste Conditioning system.

This report recommends using the SRS Bagless Transfer System to seal pucks in puck cans because the method is proven in radioactive service, SRS technical support is available, and the system is reliable.

\section{View Operations}

The three ways to view remote operations are; black and white camera, color camera, and window viewing. The can loading operations will be computer controlled, but operations require some viewing for quality assurance and safety. The advantages and disadvantages of remote viewing options are discussed in the first "View Operations" section on page 8. This report recommends the use of color cameras to view operations due to the fact that color images will give operators the most information possible.

\section{Can Swipe \& Weld Inspection}

Table 4 shows the process steps required to swipe cans and inspect welds and the equipment options for each step. The following paragraphs discuss the advantages and disadvantages of each equipment option and recommends an equipment option based on the advantages and disadvantages.

\section{Table 4 - Can Swipe \& Weld Inspection}

\begin{tabular}{ll} 
Process Steps & Equipment Options \\
\hline Swipe Can & $\begin{array}{l}\text { Pick and place machine } \\
\text { Cartesian robot }\end{array}$ \\
& Jointed arm robot \\
& SCARA robot \\
Custom swipe machine & Standard counter \\
Count Swipe & Custom counter \\
Leak check can (weld inspection) & $\begin{array}{l}\text { Mass Spectrometry } \\
\text { X-ray inspection }\end{array}$ \\
View operations & Black and white camera \\
& Color camera \\
& Window viewing
\end{tabular}

\section{Swipe Can}

The five ways to swipe cans are; a pick and place machine, Cartesian robot, jointed arm robot, SCARA robot, and a custom swipe machine. The advantages and disadvantages to using a pick and place machine, Cartesian robot, jointed arm robot, and SCARA robot are discussed in the "Load Pucks into a Can" section on page 5.

A custom swipe machine is a dedicated device that receives a can and runs a swipe around the can exterior. The following lists the advantages and disadvantages of a custom swipe machine. 
Advantages

* The machine could swipe the entire can surface.
Disadvantages

* The machine requires development.

* It uses complicated equipment inside the containment.

* It requires more floor space than a robot.

This report recommends the use of a jointed arm robot to swipe cans due to the jointed arm ability to perform many can loading operations. These operations include; maneuvering a swipe over a large portion of the can, loading and unloading the cans in the leak chamber, and loading and unloading cans into the bagless transfer system.

\section{Count Swipe}

The two ways to count swipes in the Can Loading process are a standard counter and custom counter. After the cans are welded shut and cut from the bagless transfer system, the cans are swiped and the swipes are counted to see if radioactive material is on the can exterior. The following lists the advantages and disadvantages to standard swipe counters.

Advantages

* They are commercially available.

* They are reliable.
Disadvantages

* They may need minor modifications to allow robot operation.

The following lists the advantages and disadvantages to custom swipe counters.

Advantages

* The unit will be remotely operated, or easily operated by a robot.
Disadvantages

* The system will require development.

* The unit will be less reliable than standard counters.

This report recommends using a standard counter to count swipes in the Can Loading operations since they are commercially available and reliable.

\section{Leak Check Can (weld inspection)}

The two ways to inspect the can weld are mass spectrometry and $\mathrm{x}$-ray inspection. A mass spectrometry system requires the can to be filled with helium and the can is placed in a bell jar. The bell jar is evacuated and the mass spectrometry unit analyzes the gases coming from the bell jar. If the can weld is leaking, the mass spectrometry unit will see the helium. The following lists the advantages and disadvantages of a mass spectrometry system.

Advantages

* The method is proven in radioactive applications.

* The systems are commercially available.

* Mass spectrometry units are reliable.

* The method guarantees the container is not leaking at the weld or anywhere else.
Disadvantages

* A custom bell jar must be developed.

* The bell jar must have a reusable seal. 
An x-ray weld inspection system is a x-ray emitter and an image reader. The item to be inspected is maneuvered between the emitter and reader and a computer system analyzes the images. The following lists the advantages and disadvantages of an $\mathrm{x}$-ray weld inspection system

Advantages

* The x-ray emitters are commercially available.

* X-ray weld inspections are an industry standard for weld inspections.
Disadvantages

* The system requires a custom rotator and custom image reader.

* Puck emissions may distort $x$-ray image.

* The method doesn't guarantee the can is not leaking.

* The system requires personnel shielding.

This report recommends using a mass spectrometry system to leak check and inspect the puck can welds due to its reliable radioactive service record.

\section{View Operations}

The three ways to view remote operations are; black and white camera, color camera, and window viewing. The can loading operations will be computer controlled, but operations require some viewing for quality assurance and safety. The advantages and disadvantages of remote viewing options are discussed in the first "View Operations" section on page 8. This report recommends the use of color cameras to view operations due to the fact that color images will give operators the most information possible.

\section{Open Can and Remove Pucks (Reject Cans)}

Table 5 shows the process steps required to open a reject can and remove pucks, and the equipment options for each step. The following paragraphs discuss the advantages and disadvantages of each equipment option and recommends an equipment option based on the advantages and disadvantages.

\section{Table 5 - Open Can and Remove Pucks}

\begin{tabular}{ll} 
Process Steps & Equipment Options \\
\hline Receive can & Pick and place machine \\
& Cartesian robot \\
& Jointed arm robot \\
& SCARA robot \\
Cut can & Diametrically opposed cutters \\
& Pipe cutter \\
& Torch \\
Place pucks on tray & Saw \\
& Cartesian robot \\
& Jointed arm robot \\
Handle waste & SCARA robot \\
& Cartesian robot \\
& Jointed arm robot \\
& SCARA robot
\end{tabular}


Table 5 - Open Can and Remove Pucks (Cont.)

Transport tray to puck robot

View operations
Magnetic linear transport cart

Belt conveyor

Roller conveyor

Rodless air cylinder

Magnetically coupled air cylinder

Shared workcell with puck robot

Black and white camera

Color camera

Window viewing

\section{Receive Can}

The four ways to receive and handle reject cans are; a pick and place machine, Cartesian robot, jointed arm robot, and SCARA robot. The advantages and disadvantages to using a pick and place machine, Cartesian robot, jointed arm robot, and SCARA robot are discussed in the "Load Pucks into a Can" section on page 5.

This report recommends the use of a jointed arm robot to receive and handle reject cans due to the dexterity required to handle puck cans.

\section{Cut Can}

This report only considers can cutting methods that have a low chance of damaging the pucks inside the can. For example, saws and torches could damage the pucks inside cans. The two methods to cut reject cans are; diametrically opposed cutters and a pipe cutter. Diametrically opposed cutters are two cutting wheels that rotate around the can exterior. They are positioned on opposite sides of the can during the cutting and they index inward a small amount each rotation. The following lists the advantages and disadvantages of diametrically opposed cutters.

Advantages

* The method is proven.

* The cutters are commercially available and simple.

* The method uses redundant cutters.

* The method is chip free.
Disadvantages

* Some development is required to remotely use the system in a glovebox.

A pipe cutter is one cutting wheel and two follower wheels that rotate around the can exterior. The follower wheels are on the opposite side of the can from the cutting wheel and the cutting wheel is indexed inward a small amount each rotation. The following lists the advantages and disadvantages of using a pipe cutter.

Advantages

* The method is proven.

* The cutters are commercially available and simple.

* The method is chip free.

* The system is self centering.
Disadvantages

* The systems requires some development to remotely use in a glovebox. 
This report recommends the use of diametrically opposed cutters due to the redundant cutter wheels inherent to this method and the successful use in the SRS bagless transfer system.

\section{Place Pucks on Tray}

The four ways to place pucks from the cut reject cans on a tray are; Cartesian robot, jointed arm robot, SCARA robot, and custom machine. A pick and place machine is not considered since the pucks will be randomly distributed after the can is cut open. After the pucks are placed on the tray, they will transported to the can loading system. The advantages and disadvantages to using a Cartesian robot, jointed arm robot and SCARA robot are discussed in the "Load Pucks in a Can" section on page 5 .

The following lists the advantages and disadvantages of a custom machine to load pucks on a tray.

Advantages

* The machine can incorporate the cut can function and tray loading function in one device.
Disadvantages

* The machine will have high development cost.

* The machine will have lower reliability.

* The system requires complicated equipment inside the glovebox.

This report recommends the use of a jointed arm robot to place pucks on a tray due to the dexterity required to pick up puck and place them on a tray. This jointed arm can also perform the receive and handle reject can tasks.

Handle Waste

The three ways to handle the cut can pieces, or waste, generated during the opening of reject cans are; a Cartesian robot, jointed arm robot, and SCARA robot. The advantages and disadvantages to using a Cartesian robot, jointed arm robot, and SCARA robot are discussed in the "Load Pucks in a Can" section on page 5. This report recommends the use of a jointed arm robot to handle the waste generated during the opening of reject cans due to the dexterity required to pick up random waste items and place them on a tray or basket. This jointed arm can also handle reject cans and place the pucks from the cut can on a tray.

\section{Transport Tray to Puck Loading Robot}

The five options to transport puck trays from the reject can station to the can loading system are; magnetic linear transport, belt conveyor, roller conveyor, magnetically coupled air cylinder (or rodless air cylinder), and a shared workcell with the puck loading robot. The advantages and disadvantages of using magnetic linear transport, belt conveyor, roller conveyor, and magnetically coupled air cylinders are discussed in the "Transport Trays From Elevator" section on page 2.

The advantage to sharing workcell space between the reject can robot and the can loading robot is that no transport equipment is needed. The disadvantages to sharing workcell space between the reject can robot and the can loading robot are; the method requires a collision avoidance system and the shared workcell space limits the usable workcell space of each robot. 
This report recommends that the reject can robot and can loading robot share workcell space to transfer pucks from the reject can station to the can loading station. This will minimize the equipment in the containment.

\section{View Operations}

The three ways to view remote operations are; black and white camera, color camera, and window viewing. The can loading operations will be computer controlled, but operations require some viewing for quality assurance and safety. The advantages and disadvantages of remote viewing options are discussed in the first "view operations" section on page 8 . This report recommends the use of color cameras to view operations due to the fact that color images will give operators the most information possible.

\section{DEVELOPMENT AREAS}

The following issues require further development to ensure a successful $\mathrm{Pu}$ Immobilization can loading system. The bagless transfer welder and cutter design is a low priority item since the design is similar to the existing FB-Line system.

High Priority

1. Loading pucks into cans

2. Fill can with helium and insert plug

3. Tray storage system

4. Handle filled cans (load bagless, load leak detector, etc.)

5. Handling pucks from cut reject cans
Low Priority

1. Design bagless transfer welder and cutter

2. Can Swiping

3. Helium bell jar

4. Cut reject cans

5. Handle waste (stubs, reject cans)

\section{CONCLUSIONS}

This report started with the Plutonium Immobilization Plant Process Flow Diagram for Can Loading (see Attachment 1) and made a detailed Can Loading Flow Diagram (see Attachment 2). From this detailed process flow diagram, equipment options for each step were evaluated based on equipment advantages and disadvantages. This report recommends an equipment option for each process step and Table 6 summarized these recommendations. The Can Loading processes can be accomplished remotely with the recommended equipment and a sufficient equipment development effort.

\section{Table 6 - Recommended Equipment}

\section{Process Step}

Load Pucks into cans

Transport trays from elevator

Store trays

Load pucks in cans

Fill can with helium and insert plug

Transport plugs into glovebox

View Operations

\section{Recommended Equipment}

Magnetic linear transport

Custom vertical lift

Cartesian robot

Helium atmosphere and Cartesian robot

Preload plug in puck can

Color cameras 


\section{Table 6 - Recommended Equipment (Cont.)}

Bagless Can Loadout (Seal Can)

Bagless transfer

View operations

Can swipe and weld inspection

Swipe can

Count swipe

Leak check can (weld inspection)

View operations

Open can and remove pucks (reject cans)

Receive can

Cut can

Place pucks on tray

Handle waste

Transport tray to puck loading robot

View operations
SRS bagless transfer system

Color cameras

Jointed arm robot

Standard counter

Mass spectrometry

Color cameras

Jointed arm robot

Diametrically opposed cutters

Jointed arm robot

Jointed arm robot

Shared workcell space

Color cameras 
Attachment 1 - Plutonium Immobilization Plant Process Flow Drawing

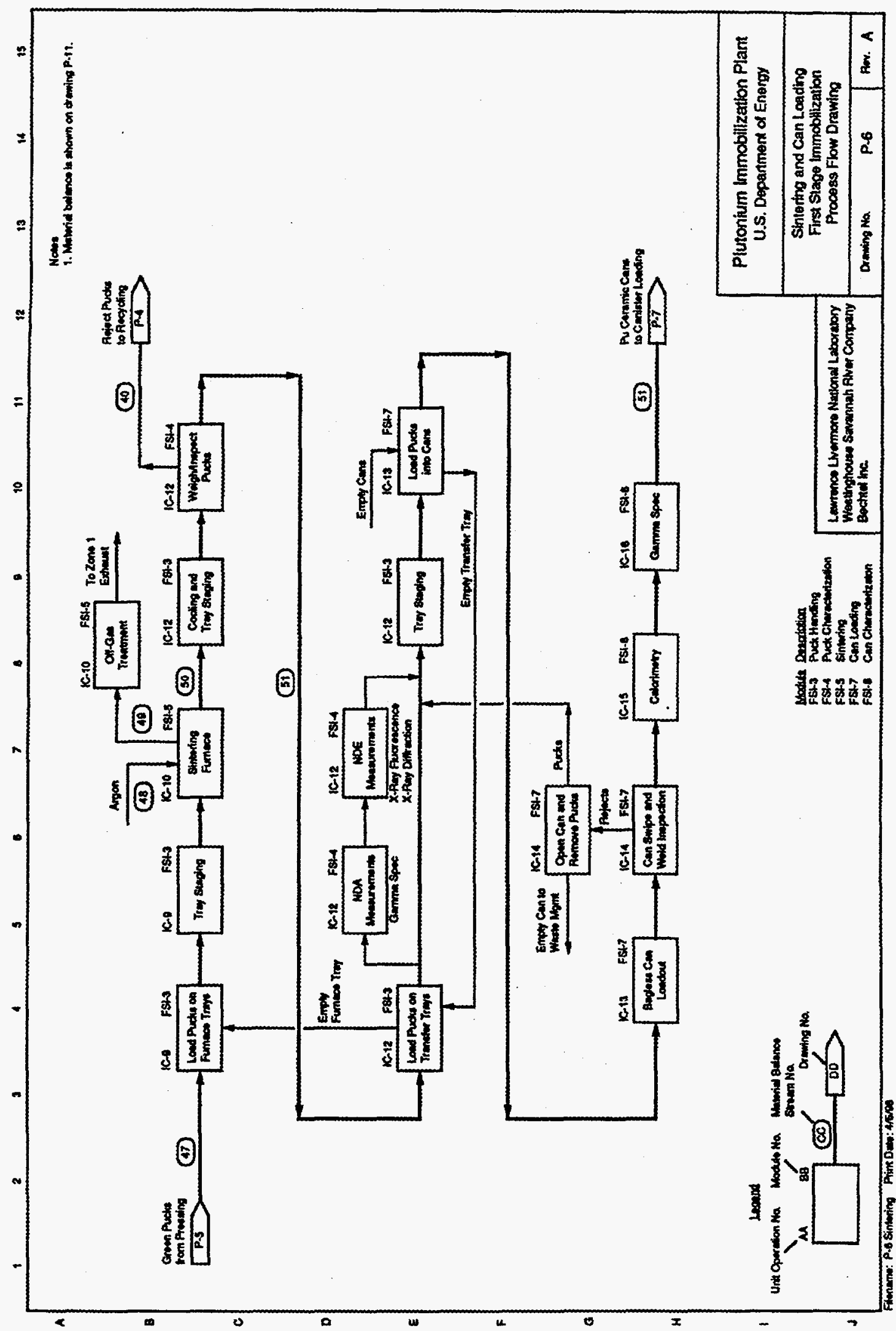



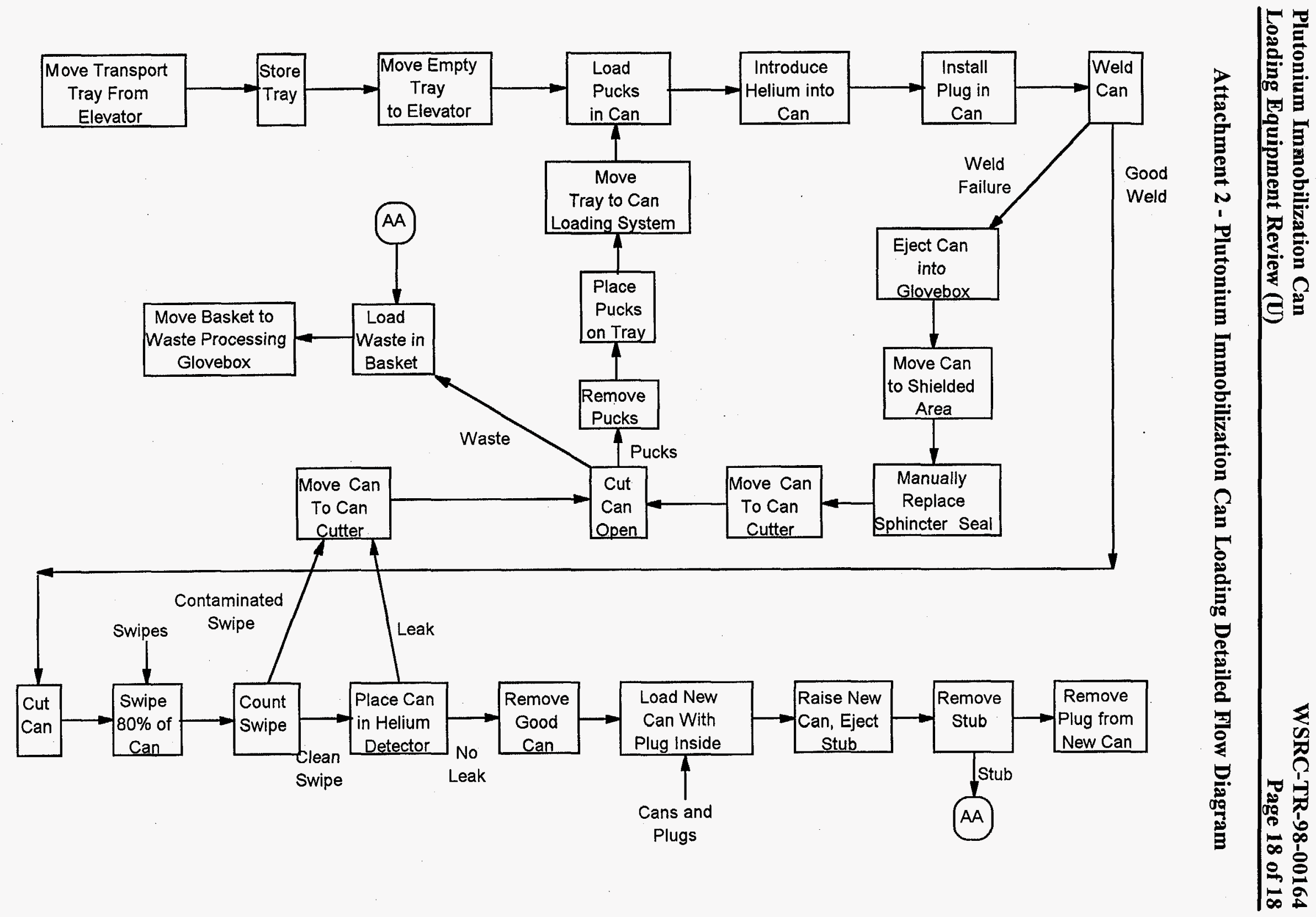